\title{
Editorial
}

\section{Rwanda Journal of Medicine and Health Sciences: new name, increased visibility}

Since 2018, the series of Rwanda Journal have split into independent Journals. It is in this context that the Rwanda Journal Series F: Medicine and Health Sciences has become Rwanda Journal of Medicine and Health Sciences. The Rwanda Journal Series F: Medicine and Health Sciences had resulted from the merger of the former Rwanda Journal of Health Sciences and Rwanda Journal Series F: Health Sciences, when public higher education institutions in Rwanda were merged to form the University of Rwanda in 2013. The change of name is intended to raise the visibility of the journal, by ensuring that it is displayed separately on the African Journals Online (AJOL), and other sites where it will be hosted. The journal can now be easily accessed with possibility of increased submissions.

The new name comes with a commitment of regularity so that a greater number of papers can be published promptly without the need for long waits. The journal aims at publishing three issues per year in January, May and September. There will be regular calls for manuscripts through various media outlets. Archives of articles published previously in Rwanda Journal Series F: Medicine and Health Sciences will remain accessible to readers.

We aim at transforming Rwanda Journal of Medicine and Health Sciences into the journal of choice that publishes the best papers and meets the criteria of being indexed in PubMed in the shortest time possible. With the support the journal is currently receiving from the African Journal Partnership Programme along with the technical support from Elsevier, our dreams are fast being realized.

\section{Prof. Jean Bosco Gahutu}

\section{Editor-in-Chief}

